increase the efficiency of the regional lending-library systems. The necessity for government aid is fully recognized, and, by implication rather than by direct statement, the pamphlet is a further indictment of the Government's inaction in this field and failure to implement the recommendations of the Advisory Council for Scientific Policy. Reference is made to an even more detailed scrutiny of the work of the North Western Regional Library System and of its requirements in that area, which was contained in a report, published this year, by J. F. W. Bryan, L. L. Ardern, G. B. Cotton and A. Glencross.

\section{New Australian Map of the Antarctic}

THE second edition of the general map of Antarctica on a scale of $1: 10,000,000$, produced by the National Mapping Office, Australia (Antarctic Division, Depart ment of External Affairs, Canberra), has recently been published. The first edition was published in 1939, and comparison of the two maps shows not only that very many more named features have been added to the latest map, but also that much of the previously unexplored coast (a dotted line in the 1939 edition) has now been filled in. This is particularly noticeable in the larger-scale inset of the Australian Antarctic Territory. The map is clearly and well produced in colour; lettering is in blue and black; mountains are lightly etched in brown; and ice fronts are shown with the date of their latest known position. Political boundaries remain the same as in 1939. The map is obtainable in Britain from Australia House, London, price $2 s$.

\section{Long Ashton Research Station : Report for 1955}

STEADy progress in the major activities of the Agricultural and Horticultural Research Station, Long Ashton, is recorded in its annual report for 1955 (pp. $224+12$ plates. Published by the University of Bristol, $1956 ; 15 s$.$) . Collaboration with the Colonial$ Office has been further developed by the appointment of two officers, one to work on problems of practical entomology and spraying at centres in the Colonial territories and the other will be concerned with engineering problems. The Section of Pomology and Plant Breeding has so far assembled sixty species towards a working collection of Ribes species which will serve as breeding material for improving blackcurrant varieties. An attempt is also being made to clarify the classification of gooseberry varieties with due regard to the complications caused by widespread virus infection. Experiments have been continued with synthetic growth substances to study their efficiency as thinning agents, for controlling preharvest drop and for accelerating ripening in apples. As a result of experiments initiated in 1944, it is suggested that the economic life of blackcurrant plantations, hitherto assumed to be ten years, can be confidently raised to fifteen years under present-day methods of management. Investigations carried out by the Fruit Nutrition Section on the cure of chlorosis of fruit trees by application of iron chelate compounds to the soil have shown that complete recovery from chlorosis during the year of treatment can be obtained by soil application of iron chelates to chlorotic pear trees provided the compounds are thoroughly watered in, or placed near the rooting zone by means of liquid soil injection. It is thought, however, that the method is uneconomic, and it was found that three to four foliar applications per season will also give control of chlorosis. In the Cider and Fruit Juice Section vintage trials of cider and perry varieties have been continued, and a standard method of fermentation combined with sterile bottling has been adopted.

\section{Arterial Arches of Birds}

IT has long been realized that the arteries near the heart and in the neck of birds vary very widely from species to species. Fred H. Glenny (Proc. United States Nat. Mus., 104, 463 ; 1955) has discussed the modifications of the pattern of the aortic arch system of birds and their significance. $\mathrm{He}$ has made a major contribution to this subject during the past sixteen years and has dissected more than 750 species and subspecies. The present memoir considers not only this work but also all that has been reported previously and what is known of the development of these vessels in birds (not a great deal). In the light of this the author has drawn up a classification of the principal patterns encountered with their sub-divisions, and so by means of a series of letters and numbers is able to express the conditions found in the different species in such a manner as to allow of ready reference and comparison. It may be noted, in passing, that the major division is into those with one or two carotid arteries. In his conclusions, he suggests that the Archaeornithes should be placed in the Sauropsida with the Reptilia, "since mere presence of feathers is not sufficient for placing them in close association with modern birds". As commonly understood, however, the Sauropsida includes Reptilia and Aves as opposed to the Theropsida, the Mammalia. This memoir contains a great deal of information in a concentrated form, and constitutes a mine of in. formation for future reference. The eleven figures contain a large number of individual diagrams, and in view of its usefulness it is a pity that many of them are not larger and clearer. Fig. 108e is stated to represent the arteries in Sphenodon punctatus, but, so far as can be judged, bears little resemblance to the condition in that animal.

\section{Screens for Meteorological Thermometers}

THE thermometers used for measuring air tem. perature and humidity must be at the same temperature as the surrounding air or at the correct wet-bulb temperature. The major source of a difference of temperature between the bulb and the surrounding air is radiation to or from the bulb. A shield must be provided over the thermometers to minimize radiative heat-exchange without impeding the flow of air past the bulbs. The most accurate instrument is the Assmann psychrometer, consisting of two small thermometers, one dry-bulb and one wet-bulb, in narrow parallel tubes made of highly polished metal through which a stream of air is drawn by a fan driven by a elockwork or, better, an electric motor. The Assmann psychrometer is expensive, and the screen most used is the "Stevenson" screen, which is a louvred box painted white and relatively large in comparison with the thermometers which it houses. The Meteorological Service of the West German Republic has recently made experiments (Ber. Deutsch. Wetterdienst, 3, No. 19; 1956), to see if a screen cheaper and more easily installed than the Stevenson screen would be satisfactory for use at auxiliary meteorological stations at, for example, farms and in forests. The screens used were four in number: large, medium and small Stevenson-type screens ; and a "shade tube" (Schattenhulse) made of polished aluminium foil $0.2 \mathrm{~mm}$. thick, $5 \mathrm{~cm}$. in diameter and $45 \mathrm{~cm}$. long, 